\title{
The Cultivation Mode of Graduate Students' English Writing Ability of Scientific Papers on Mining Engineering
}

\author{
Haiying SHEN \\ Faculty of Foreign Languages \& Cultures \\ Kunming University of Science \& Technology \\ Kunming, China \\ Shying65@126.com
}

\author{
Shuming WEN \\ Faculty of Land Resource Engineering \\ Kunming University of Science \& Technology \\ Kunming, China \\ shmwen@126.com
}

\begin{abstract}
Up till now, the development of mining industry in China has followed the road of the overseas introduction and absorption, independent innovation and technology export. Mere English reading ability can hardly meet the demands of high-level professionals to export research achievements. To improve the graduate students' ability to write English scientific papers on mining industry has become one of the main tasks to cultivate mining engineering professionals. Considering the current condition of China's test-oriented education, the mode to efficiently and quickly enhance graduate students' English writing ability of scientific papers on mining industry has been proposed, specifically, intensively reading high-level English scientific papers on mining industry, writing the Chinese version according to the requirements of the corresponding English scientific paper, rewriting the paper in English based on the Chinese version, performing language refinement and polish by experts or institutions, finally completing the paper through communication and exchange with the experts.
\end{abstract}

Keywords- mining engineering, scientific paper, cultivation of graduate students, English writing ability.

\section{Introduction}

Mining industry is to be a fundamental one of the national economy construction. Since its founding, China has witnessed three stages of mining industry development: the beginning stage of overseas introduction and absorption, the stage of independent self-development and the disseminating stage of exporting technology, which have provided the crucial support of mineral resources for the national economy and promoted the economic and social development of China.

The exchanges at home and abroad have been conducted in different depth and breadth at different stages of mining development. The initial stage mainly involves the introduction of foreign advanced technology and equipment, and the application into domestic mining development and employment after digestion and absorption. Mining engineering professionals, indispensably armed with high reading ability, study abroad, read and absorb foreign scientific and technological literature so as to improve the ability to apply the advanced technology and to actualize development and utilization of mining industry. In the 1950s when the development of mining industry of China was at such a starting stage, a lot of mining engineering professionals went to the Soviet Union to study the expertise in exploitation and utilization of ores resources. They played an active and important role in developing mining industry in China.

During the period of 1950 s to 1980 s when Chinese mining industry has underwent initiative and independent development, mining professionals carried out their independent development and utilization of Chinese mining industry applying the science and technology learnt from abroad. Mining industry then developed slowly owing to the fairly low level of developing and utilizing ores resources, and the economic and social development was relatively sluggish accordingly. With the implementation of reforming and opening policy since 1980s, mining industry has developed fast, promoting its exploitation and development of China close to the advanced international level over mere 20 years. The widely international academic and technological exchange as well as mutual or multi-way cooperation has greatly boosted the development of mining industry in China. In this period, mining engineering professionals should be good at English reading and speaking.

In the first decade of the 21 st century, China has seen a significant change in mining industry. Energy-efficient and environment-friendly development model has become the only one of mining developing; science and technology has become the crucial factor. The technology of exploiting and utilizing ores resources in China has reached to the international advanced level, making it an inevitable trend to export our mining technology and equipment in the 2020s. Under such circumstances, mining engineering professionals not only 
should be competent at English reading and speaking, but also at technical English writing to introduce our latest high-level research achievements and technology by publishing highquality academic papers.

Higher requirements of English ability for mining engineering professionals have been put forward in the new situation. Especially, technical English writhing is a must for high-level mining engineering professionals, thus how to improve this ability has become an imperative research subject for the English education of postgraduates majoring in mining engineering ${ }^{[1]}$.

\section{The Instructional Model to Improve Graduate Students' Ability to Read English Scientific Papers}

To improve postgraduates' English comprehension through intensively reading the high-standard English scientific papers on mining industry

The introduction part of an English scientific paper, a succinct generalization of the current situation and trend in the relevant research field, is vital to the entire writing process, calling for plenty of literature reading. Literature reading on the one hand enables graduates to know and keep track of the research trend, research subject and research level related to the paper to be written, so as to ensure the innovation, quality and significance of the paper. On the other hand, it can enhance reading comprehension of scientific papers written in English. The good understanding of English scientific papers lays the foundation for writing such papers in an easy-to-understand way.

In order to improve graduate students' comprehension ability of English scientific papers, intensive reading is demanded to learn the rather excellent articles in the area of mining industry. This process involves reading the citations, research method, result discussion and conclusion carefully, word for word, understanding each sentence thoroughly and grasping the thesis statement, arguments and conclusion. The abstract of papers requires repeated reading to master the gist of the research content and research conclusion.

After reading intensively a number of high-level scientific and technologic papers on mining industry, postgraduates can enhance their ability to comprehend such papers; otherwise, mere extensive reading will result in superficial understanding. To read high-level scientific and technologic papers lays the groundwork for remarkable thesis writing. It is impractical to write a high-standard scientific paper in English without the deep understanding of relevant literature written in English.

To master the English expression of scientific papers through intensive reading of high- level English scientific papers

The stylistic structure of scientific papers written in English and Chinese are similar, but the thesis statement is a big difference. Due to the interference of their mother-tongue, Chinese graduate students generally have trouble in the statement of English expression. The English learning of
Chinese graduate students is primarily test-oriented, leading to the consequence that their good command of grammar and large vocabulary do facilitate academic reading, not language production, though, owing to the tough problem of diction, tense and subtle grammatical relations when writing.

Intensively reading high-level English scientific papers on mining industry is an effective way to improve writing skills. In the process of reading, in addition to understanding the meaning of each sentence, understanding and grasp of sentence structure and expression pattern are of great importance to writing. For reading material, it is better to choose scientific papers on mining industry written in standard English by the native speaker. To express their ideas using the grammar and vocabulary they have originally learnt, Chinese graduate students tend to make up some sentences which are misleading or even incomprehensible for English native speakers because of the polysemy.

There is norm for writing of scientific papers, chiefly involving presentation and discussion of the facts, without too much wonderful description, hyperbole, personification and other forms. Accordingly, targeting in intensive reading of high-level mining scientific papers will enable you to quickly master mining technology thesis writing skills, and to advance the rapid promotion of the level of English paper writing on mining technology.

To master the English expression of scientific papers through intensive reading of high- level English scientific papers

The stylistic structure of scientific papers written in English and Chinese are similar, but the thesis statement is a big difference. Due to the interference of their mother-tongue, Chinese graduate students generally have trouble in the statement of English expression. The English learning of Chinese graduate students is primarily test-oriented, leading to the consequence that their good command of grammar and large vocabulary do facilitate academic reading, not language production, though, owing to the tough problem of diction, tense and subtle grammatical relations when writing.

Intensively reading high-level English scientific papers on mining industry is an effective way to improve writing skills. In the process of reading, in addition to understanding the meaning of each sentence, understanding and grasp of sentence structure and expression pattern are of great importance to writing. For reading material, it is better to choose scientific papers on mining industry written in standard English by the native speaker. To express their ideas using the grammar and vocabulary they have originally learnt, Chinese graduate students tend to make up some sentences which are misleading or even incomprehensible for English native speakers because of the polysemy. There is norm for writing of scientific papers, chiefly involving presentation and discussion of the facts, without too much wonderful description, hyperbole, personification and other forms. Accordingly, targeting in intensive reading of high-level mining scientific papers will enable you to quickly master mining technology thesis writing skills, and to advance the rapid promotion of the level of English paper writing on mining technology. 


\section{Extension-Rule Based Theorem Proving Method the Instructional Model to Improve Graduate Students' Ability to Write English Scientific Papers}

A good English scientific paper on mining industry requires perfect language expression, and more importantly, its scientific value and academic level. Apparently the academic value and level of the paper is fundamental, while the English language is the means. It is hard to think in English for Chinese graduate students, studying in China, the first language environment. The consideration of academic issues and language expression in the meantime often leads to the lack of logic and incoherence. The better approach is to write a high level of a scientific paper in Chinese at first, based on which then complete a high-quality scientific paper in English.

Yet the Chinese scientific paper should be written in accordance with the requirements of the English scientific paper. A typical scientific paper is composed of title, abstract, introduction, methods / experimental procedures, results, discussion, acknowledgments and references. Professor Zhou Yaoqi, School of Informatics, Indiana University, has put forward advisable suggestions about how to write these aspects well ${ }^{[2]}$. A paper starts with the abstract and introduction, but Professor Zhou advises to begin from the method and result sections, with which the author is most familiar. Besides, the subject matter can be determined only if the methods and results are better understood.

Graduate students should start working from the most familiar things, just like the readers understanding from the most familiar part. With respect of methods or experimental procedures, if the paper is concerned with new methods, techniques, or algorithms, it requires the detailed and elaborate statement and specification in a logical and reasonable way. This will help readers grasp the essentials of the new method. If the method uses the parameters, every parameter needs rationalization, applying the previously used ones, or derived from physics or mathematics, or through extensive testing and optimization. If the rationality cannot be guaranteed, the influence caused by changing it must be described; if the test of the rationality is not conducted, the explanation should be given. The development of a new research method requires various tests. The more tests there are, either collected or designed by the author, the more convincing it would be, and the more research work will be accepted and applied.

When graduate students begin to write the results section, firstly consider what the results mean. In other words, understand the test results from these aspects: whether the results tell the more profound things, whether the results could be comprehended from many different angles, whether some conclusions could be drawn through designed proof or disproof. If a new phenomenon is discovered, the result must be testified to ensure that it is not forged; it can be reduplicated under different conditions. A new method developed calls for testifying its importance and improvement comparing with the existing method.
In the results section of the paper, discussion from different perspectives or multiple tests are called for to support new discovery or to validate the importance of the new method. Once the results have been fully analyzed, the thesis statement of this paper needs to be decided, proved with supporting paragraphs and testified with data. In addition, give up the data (even the hard-earned) that have nothing to do with the thesis statement. When the sections of the methods and results have been completed, the paper writing has already been more than halfway to the success.

2. English writing based on Chinese scientific papers on mining industry

To complete a good English scientific paper, it is not enough just to translate directly the completed Chinese version into English one. Due to many differences existing between English and Chinese expressions, the literal translation often fails to achieve good results. Therefore, re-writing the English version based on the Chinese scientific paper on mining industry is the key to a good English scientific paper on mining industry.

The sentence is the smallest functional unit of the article, so sentence writing is the basis of essay writing. The most easily understandable sentence is what readers are familiar with, which is not possible for scientific papers because only the new research will be published. In fact, scientific papers usually include a lot of new terminology, so an easily understandable sentence should begin with the information that the reader has known (or just mentioned), and end with new information with a typical smooth transition from the known to the new. Before using a concept, the graduate must be clear whether he or she has already mentioned this concept or not.

In a sentence, readers want to see the action verb immediately after the subject. For a sentence describing who is doing what, readers need to find the verb to understand. If the verb and the subject too far apart, reading will be interrupted by seeking the verb, causing the sentence difficult to understand.

Readers expect that in every sentence there is only one focus which usually comes at the end of the sentence. Each paragraph should be about one point. Expressing several points of view makes it hard for readers to know the focus and to be clear about the writer's intention. The first sentence of a paragraph is supposed to tell the readers about the topic, in which case, the reader can skip this paragraph freely. The last sentence of the paragraph is expected to draw the conclusions or to tell the reader what is about in the next paragraph. The sentences should be connected logically from the beginning to the end with the flow of old information to new information.

Graduate students can complete a satisfactory English scientific paper on mining industry rewriting sentence by sentence and paragraph by paragraph on the basis of its Chinese version, in accordance with the English expression of scientific papers.

3. Refinement and polish of English scientific papers on mining industry 
The response to an English scientific paper on mining industry submitted to the editorial department of journals and magazines often says in the e-mail that "In its current state, the level of English throughout your manuscript does not meet the journal's desired standard. There are a number of grammatical errors and instances of badly worded/constructed sentences. Please check the manuscript and refine the language carefully." The editorial department requires the language refinement and polish for the paper by some expert or institution. Receipt of such notice indicates the existence of language problems in the paper. In this case, graduate students are demanded to perform the language polish and refinement in accordance with the requirements of the editing, either by themselves or turning to the help of specialized institutions who know the specification of the English scientific papers, language requirements, so as to modify the language to achieve the requirements of the editorial department.

4. To re-modify English scientific papers on mining industry

In the revision process, language experts and specialized institutions sometimes put forward some suggestions about the manuscript and point out language expression problems which cannot be modified. Graduate students should take these problems seriously, carefully compare their own English expressions and experts' modification, communicate with the experts and make themselves understood. This process is important to improve graduate students' writing ability in English. As a result, graduate students are able to figure out the reasons why their discourse expounded in the way they take for granted doesn't get across.

After refinement, polish and re-modification, the paper will meet the requirements to be published in terms of English language. The writing process and practice of English scientific papers on mining industry will also significantly improve and enhance the ability of graduate students.

\section{Conclusion}

With the development of mining engineering in China. Each stage sets different requirements of English ability for mining engineering personnel. Reading ability plays the primary role in overseas introduction, absorption and selfdevelopment. Technology export calls for mining engineering personnel to be more proficient in English speaking and writing, especially in writing of scientific papers on mining industry.

Considering Chinese graduate students' insufficiency in English writing ability resulted from test-oriented education mode, their English writing ability of scientific papers can be improved by intensively reading high-level English scientific papers on mining industry, improving their comprehension ability and mastering the expression patterns of such papers.

In the process of writing an English scientific paper on mining industry, it is crucial to rewrite the English paper based on its Chinese manuscript. As Chinese differs from English in the means of expression, it is undesirable to literally translate from Chinese to English.
After submission, graduate students are supposed to invite some expert or institution to make the language refinement and polish for the paper according to the requirements of the editorial department. This process can quickly enhance graduate students' writing ability in English through communication and exchanges with the experts. Thus their papers can meet the language requirements of English scientific papers on mining industry for publication.

\section{ACKNOWLEDGMENTS}

This work was supported in part by NSFC under Grant Nos. u0837602.

\section{REFERENCES}

[1] Shuming Wen, On Current Situation of Mineral Resources Exploitation \& Talent Demands in China, China Edu. Inno. Her. 586 (2011) 98-100

[2] Zhou Yaoqi, The Key to Good English Scientific Paper, J. Un. Sci. \& Tech., 576 (2007) 121-124 